\title{
A Flexible Interface Design for Web Directories to Accommodate Different Cognitive Styles
}

\author{
Sherry Y. Chen \\ Department of Information Systems and Computing, Brunel University, Uxbridge, Middlesex, UB8 3PH, United \\ Kingdom. E-mail: Sherry.Chen@brunel.ac.uk \\ George D. Magoulas and Dionisios Dimakopoulos \\ School of Computer Science and Information Systems, Birkbeck College, University of London, Malet Street, \\ London WC1E 7HX, United Kingdom. E-mail: gmagoulas@dcs.bbk.ac.uk
}

\begin{abstract}
Search engines are very popular tools for collecting information from distributed resources. They provide not only search facilities, but they also offer directories for users to browse content divided into groups. In this paper, we've adopted an individual differences approach to explore user's attitudes towards various interface features provided by existing Web directories. Among a variety of individual differences, cognitive style is a particularly important characteristic that influences the effectiveness of information seeking. Empirical results indicate that users' cognitive styles influence their reactions to the organization of subject categories, presentation of the results, and screen layout. We developed a set of design guidelines on the basis of these results, and propose a flexible interface that adopts these guidelines to accommodate the preferences of different cognitive style groups.
\end{abstract}

\section{Introduction}

The use of the Web has proliferated in businesses, libraries, and schools. One of the major Web services is information retrieval provide by the various search engines (Liaw \& Huang, in press). In addition to providing query tools for locating particular information, search engines also offer Web directories for users to browse contents organized into groups. In that respect, Web directories are analogues to the table of contents of a book, classifying information resources into categories according to their topics. In this context, the user interface becomes the major channel to convey information. For example, users need to be able to easily recognize information resources that match with their needs (White \& Ivonen, 2001). Tailoring

Received August 7, 2003; revised February 9, 2004; accepted February 9, 2004

(C) 2004 Wiley Periodicals, Inc. • Published online 26 October 2004 in Wiley InterScience (www.interscience.wiley.com). DOI: 10.1002/asi.20103 the interface response to each individual user or groups of users is not the traditional "one-size-fits-all" approach to interface design (Langley, 1999; Rogers \& Iba, 2000). A flexible interface should accommodate users' individual preferences, and can create a comfortable environment where users can easily identify relevant content and navigation support, freely move around, and scan results (Hong, 2003). In particular, studies of information seeking have reported that the user interface is a factor that affects users' task performance significantly, especially the speed and accuracy for locating particular information (Blandford, Stelmaszewska, \& Bryan-Kinns, 2001; Marchionini, Plaisant, \& Komlodi, 1998; Näsänen, Karlsson, \& Ojanpää, 2001). Therefore, it is critical to pay attention to issues of user interface design, and ensure that interface is friendly enough to help users get the desired results (Despotopoulos, Korinthios, Nasios, \& Reisis, 1999).

In the case of Web directories, the users are diverse in terms of preferences, skills, and needs. These heterogeneous backgrounds in user population result in a new challenge for the interface design of Web directories. In response to the challenge, research is directed towards understanding how diverse populations are accessing and using Web directories (Zoe \& DiMartino, 2000). Therefore, empirical evaluation of users' individual differences becomes paramount as it can potentially provide prescriptions for developing usercentered systems that can match with the particular needs of each user.

To this end, in this study we examine how individual differences influence users' reactions to the interface design of Web directories. Among a variety of individual difference approaches, cognitive styles, which consider an individual's preferred and habitual approach to organizing and representing information (Riding \& Rayner, 1998), have been shown to have a significant effect on users' information seeking behavior (Chen \& Ford, 1998; Ford \& Chen, 2000). However, cognitive styles are often ignored even when designing 
flexible interfaces. To fill this gap, we investigate the effects of users' cognitive styles on their perceptions and attitudes towards the interface design of Web directories by analyzing users' responses to the interface features provided by existing Web directories. We begin the article by building a theoretical framework to present the relationships between cognitive styles and user interface design. The development of the research hypotheses is presented next, then we proceed to discuss an empirical study of users' experiences of the use of existing Web directories. Subsequently, the findings of this empirical study are used to develop design guidelines, which illustrate how to integrate the preferences of each cognitive style into the development of the user interface of Web directories. Last, we develop a flexible interface for Web directories that can accommodate the preferences of different cognitive style groups.

\section{Theoretical Framework}

Cognitive style is usually described as a personality dimension that influences the way individuals collect, analyze, evaluate, and interpret information (Harrison \& Rainer, 1992). Riding and Rayner (1998) have referred to cognitive styles as an individual's preferred and habitual approach to organizing and representing information. There are a variety of dimensions of cognitive styles such as Visualier versus Verbalizer, Impulsivity versus Reflectivity, and Field Dependence versus Field Independence. Among these dimensions, Field Dependence versus Field Independence has significant impacts on users' information processing, because it reflects how well an individual is able to restructure information based on the use of salient cues and field arrangement (Weller et al., 1994).

The concept of Field Dependence originated in laboratory studies on perception by Witkin and Asch (1948) and Witkin (1950). Field Dependence describes the degree to which a user's perception or comprehension of information is affected by the surrounding perceptual or contextual field, that is, "the extent to which the organization of the prevailing field dominates perception of any of its parts" (Witkin, Oltman, Raskin, \& Karp, 1971, p. 24). The distinction between Field Dependent (FD) and Field Independent (FI) individuals is similar to that differentiating Holists and Serialists (e.g., Jonassen \& Grabowski, 1993; Riding \& Cheema, 1991). Field Dependent individuals typically see the global picture, ignore the details, and approach a task more holistically. Field Independent individuals tend to discern figures as being discrete from their background, to focus on details, and to be more serialistic in their approach to learning. It seems that Field Dependence is bipolar, value neutral, consistent across domains, and stable over time (Goodenough, 1976; Messick, 1976; Witkin, Moore, Goodenough, \& Cox, 1977; Witkin \& Goodenough, 1981). Their different characteristics are:

- Field Independence: The individuals tend to exhibit more individualistic behaviors since they are not in need of external referents to aide in the processing of information. They are more capable of developing their own internal referents and restructuring their knowledge. They are better at processing impersonal abstract material, are not easily influenced by others, and are not overly affected by the approval or disapproval of superiors (Witkin et al., 1977).

- Field Dependence: The individuals are considered to have a more social orientation than Field Independent persons since they are more likely to make use of externally developed social frameworks. They tend to seek out external referents for processing and structuring their information. They are better at documents with human content. They are more readily influenced by the opinions of others, and are affected by the approval or disapproval of authority figures (Witkin et al., 1977).

In the past 10 years, a great number of studies have found that users' cognitive styles significantly influence their reaction to the user interface in terms of user control, multiple tools, and nonlinear interaction. With respect to user control, several studies have suggested that FI individuals could particularly get benefit from the control of media choice. A study by Chuang (1999) produced four-courseware versions: animation-text, animation-voice, animation-text-voice and free choice. The results have showed that FI subjects in the animation-text-voice group or in the free choice group scored significantly higher than those in the animation-text group or those in the animation-voice group. No significant presentation effect was found for the FD subjects. Similar results were obtained by Chanlin (1998), who found that FI users did significantly better in visual control treatment, but there was no difference for FD users. Other studies have suggested that FD users prefer to have auditory cues in the systems. For example, Lee (1994) has investigated the effectiveness of auditory cueing of multimedia systems. The result shows that FD users would perform more effectively if the auditory cues were available. Marrison and Frick (1994) also claim similar results for FD users regarding the usefulness of the audio components in multimedia environments.

With regard to multiple tools, Ford and Chen (2000) conducted a study to examine how cognitive styles influence users' navigation strategies on the Web. Riding's (1991) Cognitive Styles Analysis (CSA) was administered to assess each participant's level of Field Dependence. The results indicated that FD individuals tend to build a global picture with the hierarchical map. Furthermore, Palmquist and Kim (2000) investigated the effects of cognitive styles on Web searching experience. The Group Embedded Figures Test (GEFT) was administered to identify participants' cognitive styles. They have found that FD novices tend to follow links prescribed by a Web page.

In the aspect of nonlinear interaction, Durfresne and Turcotte (1997) examined users' performance in systems with linear or nonlinear structures. Witkin's GEFT was applied to identify FD and FI individuals among the users' population. They found that FD students who used the system with nonlinear structure spent more time completing the test than those who used the system with linear structure. Field Independent individuals consulted the user guide for a longer period than FD individuals in the linear version, 
while FD individuals consulted it for longer in the nonlinear version. In addition, Ford and Chen (2001) conducted an empirical study, in which they developed two Web sites with two different navigation paths: one used a depth-first path and the other one used a breadth-first path. In the depth-first path case, each topic is presented in detail before the next topic, while the breadth-first path gives an overview of all material prior to introducing detail. Field Dependent users perform better following the breadth-first path. On the contrary, FI users outperform in the depth-first path than in the breadth-first path.

Results from these studies suggest that different cognitive style groups favor different interface features provided by Web-based applications. These studies also indicate that further empirical work is needed to identify preferences of different cognitive style groups, which might serve as guidelines for the development and evaluation of Web-based applications. In this paper we examine how cognitive styles influence users' responses to the interface features of Web directories.

\section{Development of Hypotheses}

Web-based applications features, such as nonlinear interaction, user control, and multiple tools, have an impact on users' perceptions of the system interface. In addition, as Chen and Macredie (2002) have suggested the best user interface should have options for different cognitive styles. Hence, they proposed a learning model that takes into account the needs of different cognitive styles by analyzing empirical studies concerning the effects of users' cognitive styles from 1989 to 2001. Their model suggests that:

- The FI users enjoy working independently with internal construction, while the FD users need more guidance from external support;

- The FI users are active to create their own structure to organize information; while the FD users are passive to rely on the structure presented by the material;

- The FI users prefer to use the alphabetical index to locate specific information, while the FD users prefer to use the navigation map to build a global overview.

Similar preferences for users with different cognitive styles would be expected in the context of other Web-based applications, such as Web directories. Therefore, one may hypothesize that:

H1: The FI users are less affected by external format/structure, whereas the FD users are easily influenced by external format/structure;

$\mathrm{H} 2$ : The FI users adopt an active approach in locating information, whereas the FD users adopt a passive approach in locating information;

H3: The FI users tend to focus on detailed aspects of information space, whereas the FD users tend to see a global picture of information space.

Figure 1 shows the conceptual framework of this study.

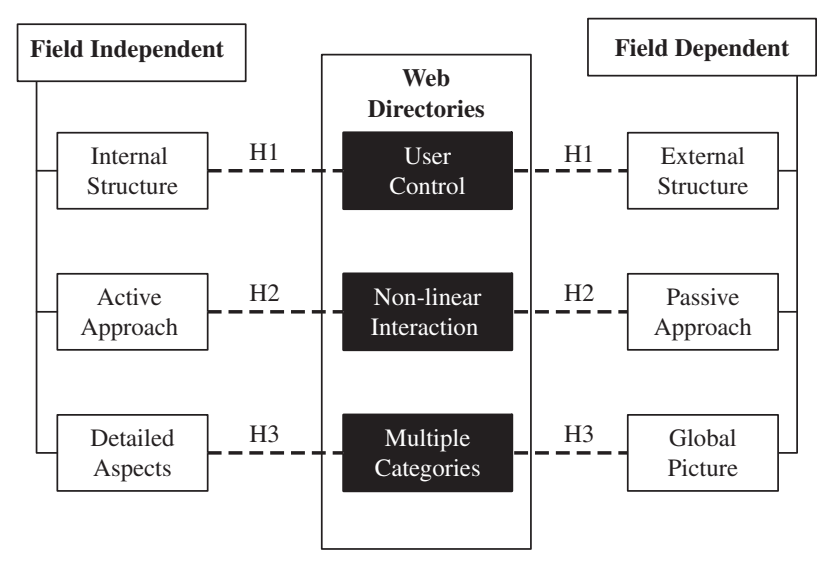

FIG. 1. Conceptual framework of the study.

\section{Experiment Design}

\section{Participants}

The study was conducted at Brunel University's Department of Information Systems and Computing. A total of 57 students participated in this study. All participants had the basic computing and Internet skills necessary to use Web directories. Despite the fact that participants volunteered to take part in the experiment, they were evenly distributed in terms of cognitive styles and gender. Figure 2 illustrates the number of participants in each group.

\section{Research Instruments}

Research instruments work as a guide to make sure that the same information is obtained from different participants. The research instruments used in this study included Cognitive Style Analysis to measure participants' cognitive styles, three Web directories with different interface features, and an exit questionnaire to identify users' perceptions and attitudes towards the interface features of the examined Web directories. The sections below introduce and explain the three instruments.

Cognitive Styles Analysis. The cognitive style dimension investigated in this study was the level of Field Dependence. A number of instruments have been developed to measure Field Dependence, including the Group Embedded Figures

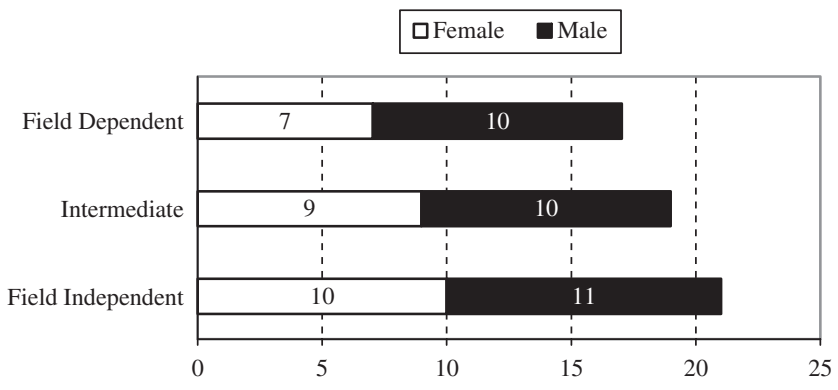

FIG. 2. Number of participants in each group. 
Test (GEFT) by Witkin et al. (1971) and the Cognitive Styles Analysis (CSA) by Riding (1991). The GEFT derives scores for Field Independence by requiring subjects to locate simple shapes embedded in more complex geometrical patterns. However, a criticism of this approach is that levels of Field Dependence are inferred from poor Field Independence performance (Ford \& Chen, 2001).

The CSA differs from the GEFT in that it includes two subtests. The first presents items containing pairs of complex geometrical figures that the individual is required to judge as either the same or different. The second presents several items each comprising a simple geometrical shape, such as a square or a triangle, and a complex geometrical figure, as in the GEFT, and the individual is asked to indicate whether or not the simple shape is contained in a complex one by pressing one of two marked response keys (Riding \& Grimley, 1999). These two subtests have different purposes. The first subtest is a task requiring Field Dependent capacity. Conversely, the second subtest requires the disembedding capacity associated with Field Independence. In this way, the CSA overcomes the GEFT limitation that affects the measures of Field Dependence and Field Independence, because Field Dependent competence is positively measured rather than being inferred from poor Field Independent capability (Ford \& Chen, 2001). In addition, the CSA offers computerized administration and scoring. Therefore, the CSA was selected as the measurement instrument for Field Dependence in this study.

The CSA measures what the authors refer to as a Wholist/ Analytic (WA) dimension, noting that this is equivalent to Field Dependence (Riding \& Rayner, 1998). Riding's (1991) recommendations are that scores below 1.03 denote Field Dependent individuals; scores of 1.36 and above denote Field Independent individuals; and scores between 1.03 and 1.35 are classified as Intermediate (Riding, 1991). In this study, categorizations were based on these recommendations.

Web directories. The experiment used a within subject design. Each participant used three specific Web directories, namely Google, AltaVista, and Lycos to cover different types of Web directories. Indeed, these three directories differ in the interface features in terms of organization of results, organization of subject categories, structure of subject categories, presentation of subject categories, arrangement of subject categories, presentation of main categories and subcategories, and location of subcategories, background colors, and text colors (see Table 1 for a detailed account). These variances provide the basis for the design of another research instrument, i.e., an exit questionnaire described in the next section.

In addition, the three Web directories differ with respect to the complexity of their interface design. For example, Google (Figure 3) was chosen as an example of concise interface

TABLE 1. Interface features of Web directories.

\begin{tabular}{|c|c|c|c|c|}
\hline Interface design & Existing approaches & Google & Lycos & AltaVista \\
\hline Arrangement of results & $\begin{array}{l}\text { Alphabetical order } \\
\text { Level of relevance }\end{array}$ & $\begin{array}{l}\sqrt{ } \\
\sqrt{ }\end{array}$ & $\sqrt{ }$ & $\sqrt{ }$ \\
\hline Arrangement of subject categories & $\begin{array}{l}\text { Alphabetical order } \\
\text { Level of relevance }\end{array}$ & $\sqrt{ }$ & $\sqrt{ }$ & $\sqrt{ }$ \\
\hline Structure of subject categories & $\begin{array}{l}\text { Many more main categories, } \\
\text { fewer levels of subcategories } \\
\text { Fewer main categories, many } \\
\text { more levels of subcategories }\end{array}$ & $\sqrt{ }$ & $\sqrt{ }$ & $\sqrt{ }$ \\
\hline $\begin{array}{l}\text { Presentation of subcategories } \\
\text { and results }\end{array}$ & $\begin{array}{l}\text { First list the subcategories, } \\
\text { then present the results } \\
\text { First present the results, } \\
\text { then list the subcategories }\end{array}$ & $\sqrt{ }$ & $\sqrt{ }$ & $\sqrt{ }$ \\
\hline Location of subcategories & $\begin{array}{l}\text { Under the main categories } \\
\text { On another page }\end{array}$ & $\sqrt{ }$ & $\sqrt{ }$ & $\sqrt{ }$ \\
\hline Main categories and subcategories & $\begin{array}{l}\text { Putting in the same menu } \\
\text { Using different menus }\end{array}$ & $\sqrt{ }$ & $\sqrt{ }$ & $\sqrt{ }$ \\
\hline Background colors & $\begin{array}{l}\text { Black } \\
\text { Blue } \\
\text { White } \\
\text { Others }\end{array}$ & $\sqrt{ }$ & $\sqrt{ }$ & $\sqrt{ }$ \\
\hline Text colors & $\begin{array}{l}\text { Black } \\
\text { Blue } \\
\text { White } \\
\text { Others }\end{array}$ & $\begin{array}{l}\sqrt{ } \\
\sqrt{ }\end{array}$ & $\begin{array}{l}\sqrt{ } \\
\sqrt{ }\end{array}$ & $\begin{array}{c}\sqrt{ } \\
\sqrt{ } \text { (Plum) }\end{array}$ \\
\hline
\end{tabular}




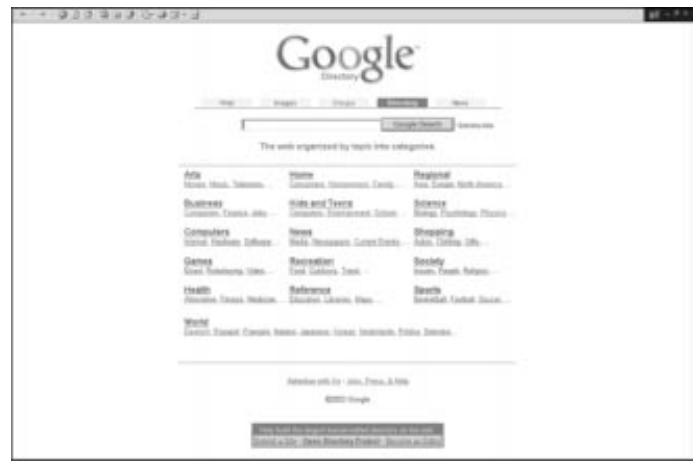

FIG. 3. Google interface design.

design, whereas Lycos (Figure 4) was chosen for its richness of features. Furthermore, AltaVista (Figure 5) adopts a design that comes in-between the other two designs. Having such variety in the interface features provides a wider range of user choices and can help to identify users' preferences.

Exit questionnaire. A paper-based questionnaire was applied to examine the research question, "What are the effects of users' cognitive styles on their perceptions and attitudes toward interface design of Web directories?" This instrument was chosen because it has the potential to collect cognitive and affective data quickly and easily (Kinshuk, 1996). Another advantage of questionnaires is that the data may be both qualitative and quantitative, allowing them to play a part in both quantitative and qualitative studies (Su, 1991). Several well-known questionnaires are available in the field of humancomputer interaction, such as the Questionnaire for User Interaction and Satisfaction (QUIS) developed by the University of Maryland (Chin, Diehl, \& Norman, 1988) and the Purdue Usability Testing Questionnaire (PUTQ) developed by Purdue University (Lin, Choong, \& Salvendy, 1997). However, this study specifically examines how users' cognitive styles influence their response to the interface design of Web directories. Therefore, we decided to design the questionnaire ourselves, instead of using an existing questionnaire.

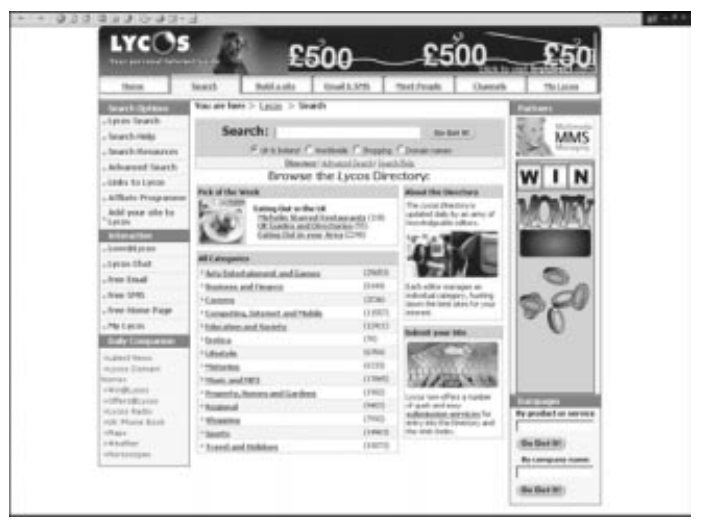

FIG. 4. Lycos interface design.

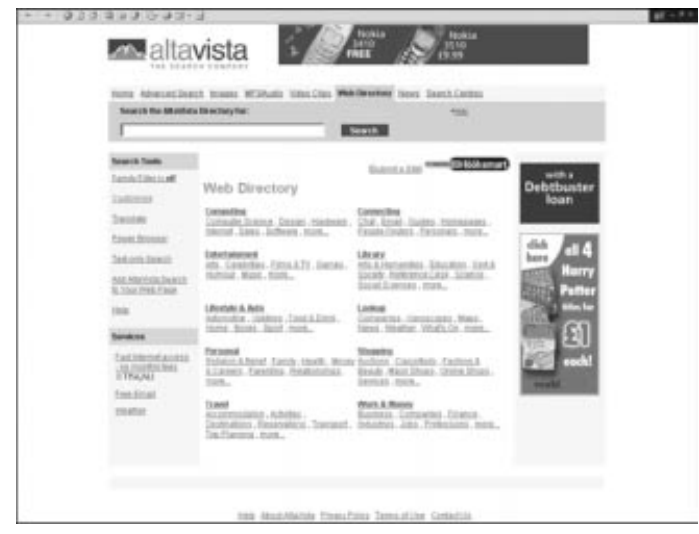

FIG. 5. AltaVista interface.

The questionnaire covered a wide range of design issues and was constructed by combining the Web directory features described in Table 1 with specific characteristics and requirements of Field Independent and Field Dependent users, which have been identified in our previous work on the development of a cognitive model for these two cognitive style groups (Chen, 2002a). In this study, the exit questionnaire, which contained both open-ended and closed questions, was designed using a semistructured format. Thirty closed questions were applied to identify the participants' perceptions toward the features of interface design provided by the Web directories, including: (a) content presentation, (b) screen layout, and (c) difficulties and problems. In addition, there were three open-ended questions, which were related to students' opinions about the strengths and weaknesses of each Web directory and the problems that they encountered. The participants were requested to provide their opinions in their own words, in the relevant space provided. It took approximately $15 \mathrm{~min}$ utes to respond to all questions of the questionnaire.

\section{Design of Task}

The purpose of this study was to find out how various interface features provided by Web directories are perceived by users with different cognitive styles. To identify users' real perceptions, participants were asked to perform a practical task, which includes two activities in each Web directory (see Table 2). The task was designed to focus on how users would browse through the information included in each Web directory and on the way content is presented to them.

The information included in the three Web directories varies with respect to the subject content. This is reflected in the task activities of Table 2 . However, all the activities considered are of the same nature as they aim at finding different types of information. One and a half hours were allocated for each participant to use all of the directories and complete the task activities.

\section{Experimental Procedures}

The experiment was conducted using the three Web directories, i.e., Google, AltaVista, and Lycos, accessed through 
TABLE 2. Task activities used in the study.

\begin{tabular}{lcc}
\hline Web directory & Activity 1 & Activity 2 \\
\hline Google & $\begin{array}{c}\text { Find Web sites of } \\
\text { Chinese music. }\end{array}$ & $\begin{array}{c}\text { Find software to play } \\
\text { bingo with } \\
\text { friends. }\end{array}$ \\
Lycos & $\begin{array}{c}\text { Find out instructions } \\
\text { on preparing a résumé. }\end{array}$ & $\begin{array}{c}\text { Find a description of } \\
\text { Manchester Library } \\
\text { and its information } \\
\text { AltaVista }\end{array}$ \\
& $\begin{array}{c}\text { Find the birth date and } \\
\text { the death date of } \\
\text { Vincent van Gogh. }\end{array}$ & $\begin{array}{c}\text { Find a glossary of } \\
\text { theological terms. }\end{array}$ \\
\hline
\end{tabular}

Microsoft Internet Explorer. The following procedures were applied:

1. Participants were given a task sheet, which described the task activities that they needed to complete with each Web directory. One participant carried out the experiment at a time.

2. Participants were observed while they were carrying out the tasks with Web directories, and clarifications were given when requested.

3. Participants were asked to reflect on their opinions to the Web directories by completing a paper-based exit questionnaire.

4. The CSA was used to classify participants' cognitive styles into Field Independent, Intermediate, or Field Dependent.

\section{Data Analysis}

To investigate the users' opinions on the use of the Web directories, the data collected from closed statements of the questionnaire were coded for analysis using the Statistical Package for the Social Sciences (SPSS) for Windows (release 10.0). The independent variable was the participants' cognitive styles. The dependent variables include participants' task performance and their reactions to the interface design of Web directories. The former was evaluated by the total time spent for completing the task and the latter was the participants' choices from a range of options in the exit questionnaire. The dependent variables were analyzed against the independent variable using frequency tables. The outputs of the frequency tables were examined to find differences among the three cognitive style groups.

\section{Discussion of the Results}

Data obtained from the exit questionnaire were used to identify participants' perceptions and attitudes toward interface features provided by the Web directories. Among 30 closed statements, 10 items have shown important meaning to the interface design of Web directories, especially related to main categories, results arrangements, screen layout, and color choices. In addition, we found that there is a close relationship between users' performance and attitudes.

\section{Main Categories: Level of Detail and Organization}

Field Dependent and Field Independent users showed different preferences with regards to the number and the levels of detail of the subject categories. Eleven FD users $(65 \%)$ preferred Web directories that present many more main categories, but with fewer levels of subcategories. On the contrary, 15 FI users $(71 \%)$ favored Web directories that are divided into a small number of main categories, but include many more levels of subcategories. A possible explanation for such a difference between FD and FI individuals is their separate tendencies to adopt holistic and serial strategies. Presenting many more main categories with fewer levels of subcategories can help users to get a global view of the information space, so it matches with the holistic strategies used by FD users, who tend to see the global picture, ignore the details, and approach a task more holistically (Ash, 1986). Presenting fewer main categories with many more levels of subcategories can support the serialistic approaches taken by FI users, who concentrate on procedural details (Pask, 1976) and have more focused thinking (Ford, Wilson, Foster, Ellis, \& Spink, 2002).

In addition, FI and FD users also favored different ways for the organization of the main categories. Thirteen FI users $(62 \%)$ consider alphabetical order as an effective way to organize the main categories. On the other hand, 11 FD users $(65 \%)$ appreciated that categories can be presented based on the level of their relevance. A possible interpretation of this finding is that FI individuals tend to apply more active strategies to engage in search tasks (Witkin et al., 1977). The alphabetical order provides users with a means to locate particular information without going through a fixed path, which matches with FI users' active strategies. Conversely, FD users tend to take a passive approach by relying on salient cues (Davis \& Cochran, 1989) and have more difficulties in separating the individual parts within a whole (Witkin et al., 1977). The level of relevance of the categories is an additional guide to help them in finding out the meaningful information.

\section{Results Arrangement: Alphabetical Order Versus Relevance}

Users attitudes to the arrangement of the browsing results exhibit similarities with the results detailed in the "Main Categories: Level of Detail and Organization" section above. Alphabetical order also seems to be an effective way to arrange results for FI users $(N=12,57 \%)$. On the other hand, FD users $(N=10,59 \%)$ have a preference for the results to be presented based on the level of their relevance. Again, these findings suggest that FI users are strong in perceptual and conceptual tasks and actively segment information into relevant parts (Goodenough, 1976). In contrast, FD users prefer to be guided in the processes of seeking information (Chou \& Lin, 1997 ) and there is a need to provide them with extra support.

This finding is echoed in participants' responses to another question, where $10 \mathrm{FD}$ users (59\%) said that straightforward identification of relevant results is the most important thing 
for them to locate information within Web directories. Once more, this reveals that extra guidance may be useful in supporting FD users during interaction with a complexstructured system. However, 11 FI users $(52 \%)$ regarded understandable headings and subheadings as the most important thing to locate information. This may be due to the fact that FI individuals are very goal-oriented, so understandable headings and subheadings can help them to reach the goal quickly. The aforementioned findings suggest that different cognitive style groups prefer different ways to organize information. Designers should consider their different requirements to develop Web directories.

\section{Screen Layout: Externally Versus Internally Imposed Structure}

Screen layout is the way information is presented on the screen (Lingard, 1994). The results of our study showed that different cognitive style groups favored different modes of information presentation. Eleven FD users (65\%) prefer Web pages in which subcategories are listed first, followed by the corresponding results, while 15 FI users (71\%) said that they appreciate seeing the results first, and then the subcategories. Listing the subcategories first can help a FD user to understand the available information resources to get an overview of the subject content. Presenting the results first is beneficial to FI users that aim to access their targets directly. This is in line with the result shown in the "Main Categories: Level of Detail and Organization" section above that FD users tend to follow a holistic approach, whereas FI users prefer to use serial strategies.

Furthermore, FD and FI users have different preferences to present the relationships between the main categories and the subcategories. Eleven FD users (65\%) thought that main categories and subcategories should be presented on different pages. Conversely, 16 FI users (76\%) appreciated that the main categories and subcategories were presented on the same page, and 10 FI users (48\%) preferred that the subcategories be placed under the main categories. It may be because FD individuals prefer the external structure presented by the material (Ford, Wood, \& Walsh, 1994), and have more difficulties dealing with confusion, complexity, and illstructured presentation (Witkin et al., 1977). Presenting the main categories and subcategories on different pages may cause less confusion to FD users and help them decide which category is the most suitable choice. On the other hand, FI individuals use their own internal structure to organize information (Reiff, 1996), so too many categories presented on the same page do not hinder them in finding information. These results imply that a FD user needs clear structure and reinforcement in the use of Web directories. The presence of massive information and the absence of clear structure may delay the FD users' information seeking. However, the structure of the Web directories does not interfere with the FI users, whose cognitive skill is good in restructuring. It is the FI users who can work well in an unstructured environment. Nevertheless, the designers of Web directories cannot ignore the needs of the FD users who prefer to follow external cues, so the system should provide them with authoritative guidance to restructure the information.

\section{Color Choices: Emphasizing High Contrast Combinations}

The results reported so far indicate that FI and FD individuals favor different ways of information organization and screen layout. However, it is surprising that they have similar preferences as to color presentation. Both prefer white for the background $(\mathrm{FI}=11,52 \% ; \mathrm{FD}=9,53 \%)$. Moreover, they consider black as a suitable color for the text $(\mathrm{FI}=10$, $48 \%$; FD $=9,53 \%$ ). This suggests that both of them consider high contrast between background and text colors as an effective way to present information. This is likely due to the ability of humans to perceive objects standing out against a background. With the high contrast combination, the text is easily discernible from the background and therefore becomes readily perceived by human sight (Travis, 1991).

These findings echo those of previous studies (Lewis, 2002; Ling \& Schaik, 2002), which found that high contrast combinations could improve text readability and reduce the reading time, hence users could find information quickly at a Web site with high contrast background and text colors. These findings also support Hix and Hartson's (1993) Interface Design Guidelines, which state that high contrast color combinations draw users' attention. For the development of Web-based applications, the use of high contrast color combinations that highlight interface elements clearly is essential.

\section{Users' Performance and Perceptions: Matching/Mismatching}

The other similar preference among different cognitive style groups is that most participants liked the simple interface design of Google. Twelve FD users (66\%) and 16 FI users $(71 \%)$ agreed they liked the overall interface design of Google. In addition, the results showed that users performed better using the Google directory in terms of time spent in completing the task, i.e., Google: 17.7 minutes; AltaVista: 23.2 minutes; Lycos: 24.9 minutes. It is probably because Google provides a simple interface design, showing only necessary information and tools on the interface. As indicated by Yu and Lin (1999), information and objects should not be included on a user interface unless there is a compelling need for them and they add significant value to the application. Evidence provided by this study suggests that the most important principle of interface design may be one of simplicity, which can enhance trust towards the service provider on the Web (Karvonen, 1999).

However, FD and FI users have different interfaces that they least favored. Ten FD users (59\%) considered that AltaVisa's interface was their least favorite, whereas 15 FI users $(71 \%)$ regarded Lycos's interface as their least favorite. An interesting finding is that such perceptions seem to influence their performance in locating information with three different Web directories. In the Google directory, the FI and 
TABLE 3. Evidence in support of the hypotheses.

\begin{tabular}{|c|c|c|c|c|}
\hline \multicolumn{2}{|c|}{ Field Independent (FI) } & \multicolumn{3}{|c|}{ Field Dependent (FD) } \\
\hline Evidence & & Hypotheses & & Evidence \\
\hline $\begin{array}{l}\text { They prefer that the main categories } \\
\text { and subcategories are presented } \\
\text { on the same menu; } \\
\text { They prefer that the subcategories } \\
\text { are placed under the main categories. }\end{array}$ & $\begin{array}{l}\text { FI users are less affected by } \\
\text { external format/structure. }\end{array}$ & H1 & $\begin{array}{l}\text { FD users are easily } \\
\text { influenced by external } \\
\text { format/structure. }\end{array}$ & $\begin{array}{l}\text { They prefer that the main categories } \\
\text { and subcategories are presented on } \\
\text { different menus; } \\
\text { They prefer that the subcategories } \\
\text { are placed on another page. }\end{array}$ \\
\hline $\begin{array}{l}\text { They prefer to find the particular } \\
\text { subject categories and results in } \\
\text { alphabetical order and then find } \\
\text { information on their own; } \\
\text { Understandable headings and } \\
\text { subheadings are important to them. }\end{array}$ & $\begin{array}{l}\text { FI users adopt an active } \\
\text { approach in locating } \\
\text { information. }\end{array}$ & $\mathrm{H} 2$ & $\begin{array}{l}\text { FD users adopt a passive } \\
\text { approach in locating } \\
\text { information. }\end{array}$ & $\begin{array}{l}\text { They prefer to find both subject } \\
\text { categories and the related results } \\
\text { arranged on the basis of their } \\
\text { relevance; } \\
\text { Straightforward identification of the } \\
\text { relevant results is important } \\
\text { to them. }\end{array}$ \\
\hline $\begin{array}{l}\text { They prefer that the Web directories } \\
\text { provide fewer main categories that } \\
\text { each one includes many more levels } \\
\text { of subcategories; } \\
\text { They prefer that the Web directories } \\
\text { first present the results, then list } \\
\text { the subcategories. }\end{array}$ & $\begin{array}{l}\text { FI users tend to focus on } \\
\text { detailed aspects of the } \\
\text { information space. }\end{array}$ & $\mathrm{H} 3$ & $\begin{array}{l}\text { FD users tend to see the } \\
\text { global picture of the } \\
\text { information space. }\end{array}$ & $\begin{array}{l}\text { They prefer that the Web directories } \\
\text { provide many more main } \\
\text { categories with fewer levels } \\
\text { of subcategories; } \\
\text { First present the results, } \\
\text { then list the subcategories. }\end{array}$ \\
\hline
\end{tabular}

FD user spent a similar amount of time in completing the task activities (FI user: 17.5 minutes; FD users: 17.9 minutes). In the AltaVista directory, the FI users performed better than the FD users (FI user: 18.8 minutes; FD users: 27.6 minutes). Conversely, the FD users outperformed the FI users in the Lycos directory (FD user: 20.1 minutes; FI users: 29.6 minutes). These results are in line with that of a previous study (Chen, 2002b), which found that positive perceptions enhance users' performance and negative attitudes hinder users' performance. The findings also echo the views of Fullerton (2000) and Ford and Chen (2001), who showed that users' performed better in a system design matching their preferences, while their performance is reduced in a mismatched condition.

\section{Summary}

The results mentioned in the above sections indicated that FI and FD users showed different attitudes to the interface features of Web directories. Table 3 provides evidence regarding the validity of the hypotheses.

\section{Development of Guidelines}

The findings discussed in the previous section can help develop an understanding of how interface features of Web directories are perceived by users with different cognitive styles. They represent the preferences of each cognitive style, but also provide an overall picture of users' need in using Web directories. The findings can be used to develop guidelines for the design of Web directories that suit the preferences of each individual. Table 4 presents the guide- lines, drawing on the preceding results. These guidelines have been developed to present the preferences of FI and FD users and are composed of two parts. The first part is the specific design consideration that should be followed when developing a Web directory, and the second part outlines the purpose of incorporating such consideration into the design.

\section{Design of a Flexible Interface}

The discussion presented above supports the argument that accommodation of users' individual differences is a central issue in the interface design of Web directories. For a Web directory to be implemented successfully, interface design should reflect each user's individual needs to allow users to develop their own information seeking strategies. As suggested by previous studies (Carter, 2002; Chen \& Macredie, 2004; Leader \& Klein; 1996), users with different characteristics tend to develop and use different strategies in a user interface, and individual differences, especially cognitive styles, are the most common cause of variations in human-computer interaction activities. Therefore, a welldesigned interface is effective and crucial in accommodating these differences (Hook, 2000). Hence, Web directories should be developed to support the unique needs of each cognitive style group. More specifically, the user interfaces provided by Web directories should be flexible enough to offer multiple options tailored to the distinctive cognitive styles of different groups of users. Only when each individual's needs are met can his or her satisfaction be increased (Ke, Kwakkelaarb, Taic, \& Chen, 2002).

In this section, we propose an "Intelligent Directory" through the use of a flexible interface, which provides users 


\begin{tabular}{|c|c|c|c|c|}
\hline \multicolumn{2}{|c|}{ Field Independent } & \multicolumn{3}{|c|}{ Field Dependent } \\
\hline Purpose & Interface consideration & Web directory & Interface consideration & Purpose \\
\hline $\begin{array}{l}\text { Locate particular } \\
\text { information directly. }\end{array}$ & $\begin{array}{l}\text { Sorting by alphabetical } \\
\text { order. }\end{array}$ & $\begin{array}{l}\text { Arrangement of } \\
\text { results }\end{array}$ & $\begin{array}{l}\text { Sorting by level of } \\
\text { relevance. }\end{array}$ & $\begin{array}{l}\text { Offer extra guidance to help } \\
\text { users to judge the relevance } \\
\text { of the results. }\end{array}$ \\
\hline $\begin{array}{l}\text { Choose the subject categories } \\
\text { that users want. }\end{array}$ & $\begin{array}{l}\text { Sorting by alphabetical } \\
\text { order. }\end{array}$ & $\begin{array}{l}\text { Presentation of } \\
\text { subject categories }\end{array}$ & $\begin{array}{l}\text { Sorting by level of } \\
\text { relevance. }\end{array}$ & $\begin{array}{l}\text { Offer extra guidance to help } \\
\text { users to choose the subject } \\
\text { categories. }\end{array}$ \\
\hline $\begin{array}{l}\text { Help to focus on procedural } \\
\text { details. }\end{array}$ & $\begin{array}{l}\text { Fewer main subject categories, } \\
\text { but with many levels of } \\
\text { subcategories. }\end{array}$ & $\begin{array}{l}\text { Number of subject } \\
\text { categories }\end{array}$ & $\begin{array}{c}\text { Many more main subject } \\
\text { categories, but with fewer } \\
\text { levels of subcategories. }\end{array}$ & $\begin{array}{l}\text { Create an overall picture of the } \\
\text { information space. }\end{array}$ \\
\hline $\begin{array}{l}\text { Allow users to develop their } \\
\text { own knowledge structure. }\end{array}$ & $\begin{array}{l}\text { Main categories and subcategories } \\
\text { are placed on the same menu } \\
\text { or the subcategories are placed } \\
\text { under the main categories. }\end{array}$ & $\begin{array}{l}\text { Place of main and } \\
\text { subcategories }\end{array}$ & $\begin{array}{l}\text { Place main categories and } \\
\text { subcategories on different } \\
\text { menus or different pages. }\end{array}$ & $\begin{array}{l}\text { Reduce confusion and help } \\
\text { users to choose the subject } \\
\text { categories easily. }\end{array}$ \\
\hline Reach the target directly. & $\begin{array}{l}\text { Present the results first, then list } \\
\text { the subcategories. }\end{array}$ & $\begin{array}{r}\text { Arrangement of } \\
\text { screen layout }\end{array}$ & $\begin{array}{l}\text { List the subcategories first, } \\
\text { then present the results. }\end{array}$ & $\begin{array}{l}\text { Provide users with an overview } \\
\text { of the available resources. }\end{array}$ \\
\hline $\begin{array}{l}\text { Provide a high-contrast } \\
\text { combination. }\end{array}$ & Black and white colors. & $\begin{array}{l}\text { The choice of text } \\
\text { and background } \\
\text { colors }\end{array}$ & Black and white colors. & $\begin{array}{l}\text { Provide a high contrast } \\
\text { combination. }\end{array}$ \\
\hline
\end{tabular}

with a variety of means to find information (Archer, Head, \& Yuan, 1996). In the intelligent directory, a single flexible interface contains various options to accommodate users with different cognitive styles. The main design rationale is to provide rich navigational facilities and multiple presentation formats, so that such comprehensive features and functionalities can help users to be more flexible in making their own information seeking strategies. The detailed design implications are discussed below.

\section{Offering Successive Options}

Results of the study presented in the section on screen layout show that FD and FI users favor different ways to present the relationships between main categories and subcategories. It is helpful to FD users that the main categories and subcategories are presented on different pages (e.g., Lycos, see Figure 4). In contrast, FI users favorable approach is to have the main categories and subcategories listed on the same page, especially under the main categories (e.g., Google, see Figure 3). It seems that FD and FI users demonstrate extremely different preferences to the presentation of subject categories. Therefore, designers of Web directories should consider providing options that will allow both FD and FI users to feel comfortable with their interactions. One approach is to offer successive options, as will be explained below, and thus provide an interface that can consider the needs of both FD and FI users.

As shown in Figure 6, initially the Web directory only presents the main categories, which matches with the preferences of FD users. To meet with the needs of FI users, when users move the mouse to the main category that they are interested in, a type of stretch text is used to present the various subcategories associated with the main category (Figure 7). In this way, the Web directory not only presents the main categories and subcategories with clear structure, which can help FD users choose the relevant subject categories, but also lists the subcategories on the same page, which allows FI users to access detailed information directly.

\section{Switching Visual Cues}

This study indicates that users' cognitive styles have strong interactions with their information seeking strategies. As shown in the section, "Results Arrangement: Alphabetical Order Versus Relevance," FI users consider alphabetical order as an effective way to organize results. On the contrary, FD users appreciate that the results can be presented based on their level of relevance. This suggests that a Web directory should provide visual cues for FD users to find out the relevant information. However, such cues can be switched off, in case they irritate FI users. The flexible interface that we propose applies switching to visual cues to accommodate the individual differences between FD and FI users. Figure 8 shows an interface design that not only presents the results alphabetically, but also indicates their level of relevance by using visual cues, i.e., the number of asterisks (*). In this way, both the preferences of FI users, i.e., alphabetical order, and the needs of FD users, i.e., the indication of the level of the relevance, can be considered in a single interface. To avoid annoying FI users, the visual cues for the level of relevance can be switched off by clicking the link "Hide Relevance." In that case, the Web directory will present the results without indicating the level of their relevance (see Figure 9). Likewise, the visual cue can be switched on again by clicking the link "Show Relevance." 


\section{Intelligent Directory}

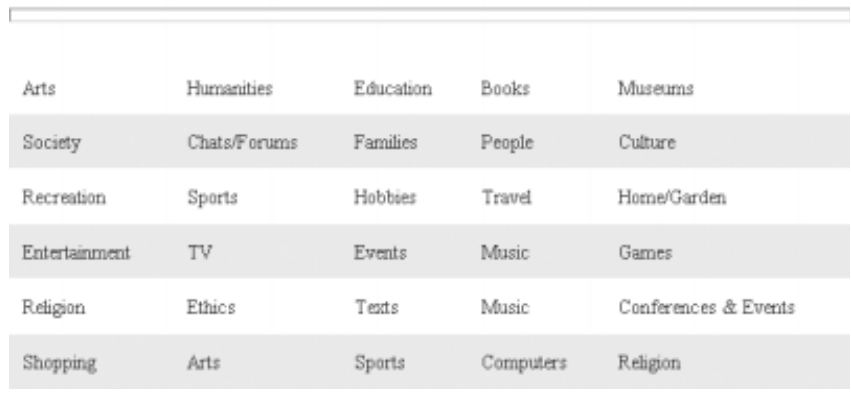

FIG. 6. Presentation of main categories to FD users.

\section{Using Scrolling Menus}

As we have established, different cognitive style groups have different preferences to organizing the main categories and subcategories. Field Independence users prefer to choose among a small number of main categories, but they want to see information organized into several levels of subcategories. On the contrary, FD users appreciate that the Web directory can provide them with many main categories to see all of the available resources, but with less levels of subcategories. It suggests that there is a need to provide a facility to arrange the organization of the categories that can match the needs of both groups. Figure 10 shows a Web directory, which organizes information into three main categories. This style meets the preferences of FI users, but it will cause a problem to a FD user who wants to visualize the entire information space. To alleviate this situation we use a horizontal

\begin{tabular}{|c|c|c|c|c|}
\hline Arts & Humanities & Education & Books & Muscums \\
\hline Thematic & \multicolumn{3}{|c|}{ Reference Web Directories Shopping and services } & Crafts more... \\
\hline Society & Chats/Forums & Families & People & Culture \\
\hline Recreation & Sports & Hobbies & Travel & Home/Garden \\
\hline Entertainment & TV & Events & Music & Games \\
\hline Religion & Ethics & Texts & Music & $\begin{array}{l}\text { Conferences \& } \\
\text { Events }\end{array}$ \\
\hline Shopping & Arts & Sports & Computers & Religion \\
\hline
\end{tabular}

FIG. 7. Presentation of subject categories to FI users using stretch text.

scrolling menu (Figure 11). Thus, when an FD user moves the mouse to one of the three categories, the horizontal scrolling menu will offer the relevant concepts for the particular category. This facility can help FD users get an overview of the whole information space provided by the Web directory for each category, offering FI users concise style to organize information into only three main categories.

\section{Presenting Multiple Frames}

This study indicates that different cognitive style groups have different preferences in regard to the arrangement of subcategories and results. Field Dependence users tend to prefer the Web directories in which subcategories are listed first, followed by the relevant results, while FI users appreciate seeing the results first, and then the subcategories. One

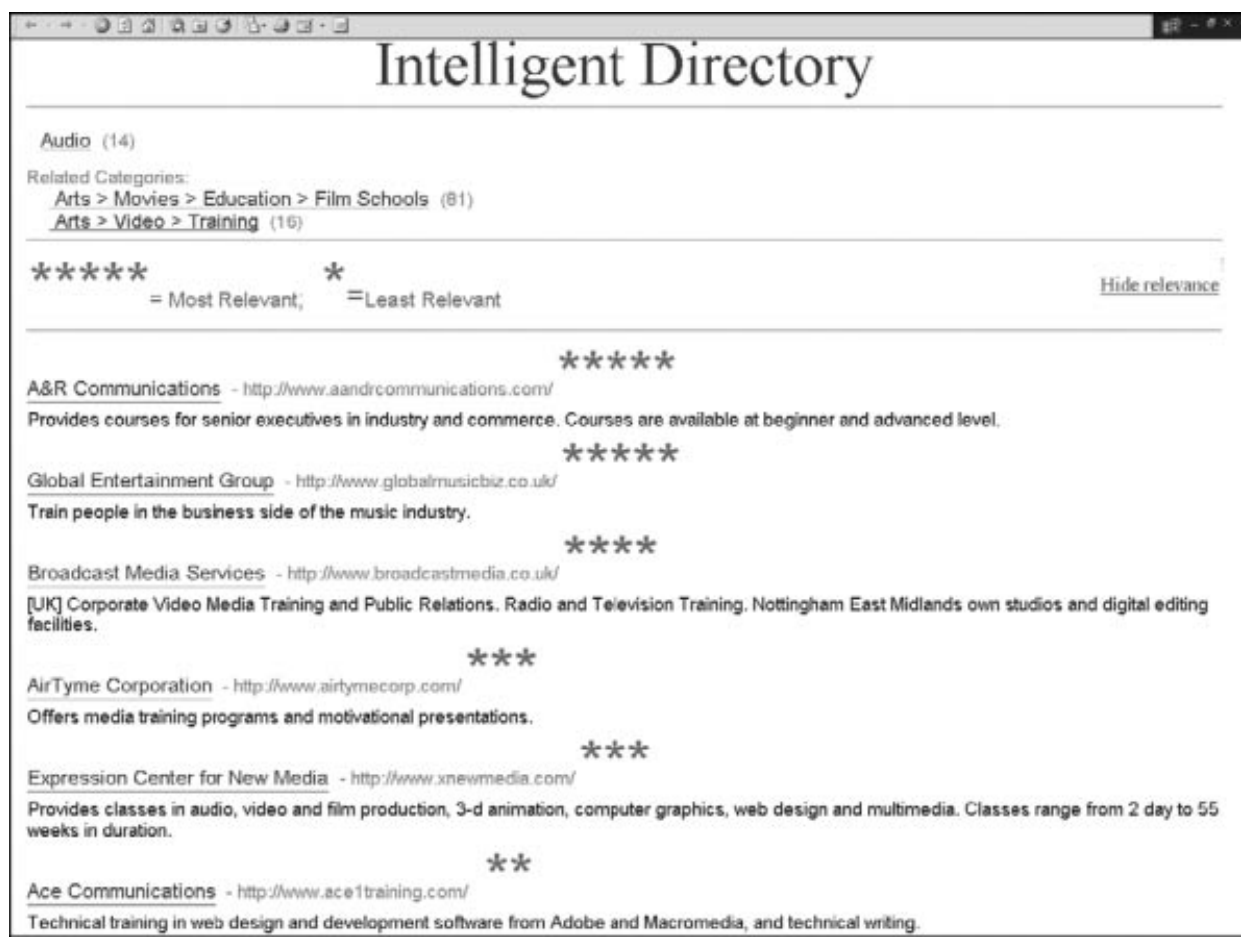

FIG. 8. Presentation of results to FD users. 


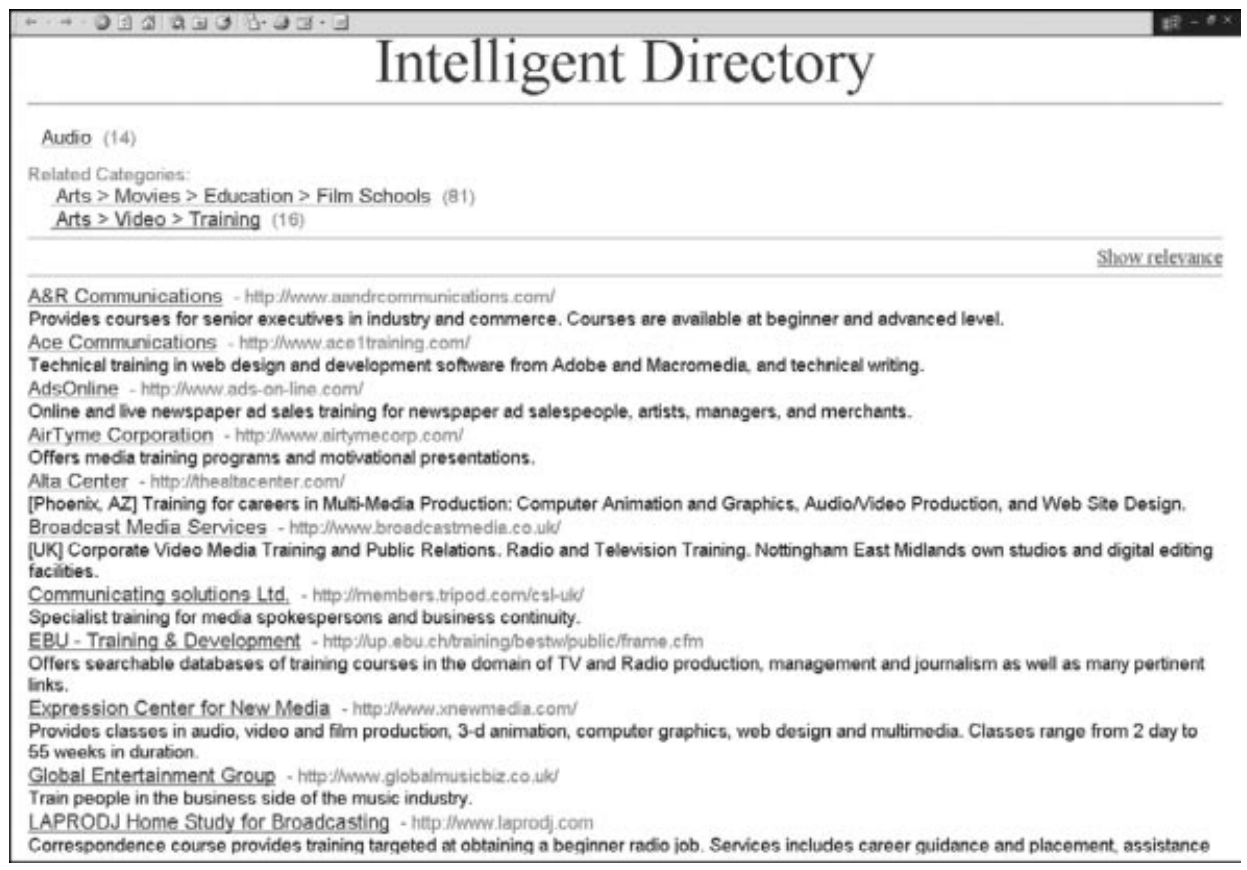

FIG. 9. Presentation of results to FI users.

\section{Intelligent Directory}

\section{Arls \& Hurramilie:}

Social Sciences

Science

FIG. 10. Organization of main categories for FI users.

of the solutions to accommodate their different preferences is to allow the users to see both the results and subcategories at the same time by using multiple frames. Multiple frames can provide navigation controls in one frame that always stay visible, even if the contents of another frame change (Hobbs, 1999). Figure 12 shows a Web directory, which uses two frames to present information. The left frame lists the subcategories for FD users to see all of the available resources, and the right frame allows FI user to examine the results directly. When the users click on a relevant result from the right frame, the corresponding Web page will be presented. However, the left frame will not change to let users see all of the available resources.

\section{Providing Additional Support}

This study indicates that FI and FD users favored different ways to organize the subject categories. The FI users prefer that subject categories be arranged in alphabetical order. On the contrary, FD users appreciate that the subject categories can be presented on the basis of the level of their relevance. This suggests that a Web directory should not only arrange the subject categories alphabetically, but also should provide additional support for FD users to find out the relevant information. Figure 13 shows an example of
Intelligent Directory

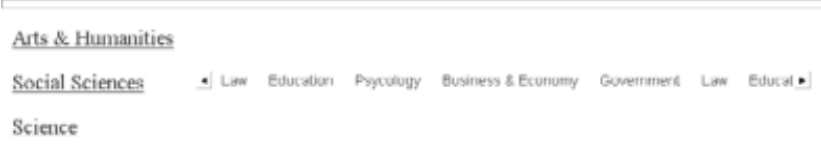

FIG. 11. Organization of main categories for FD users. interface design that presents the subject categories in alphabetical order. However, FD users can get additional support to identify the associated subject categories by clicking the $\mathrm{R}$ icon. Subsequently, the relevant subject categories, for example, "Arts \& Humanities" and "Design \& Arts," are marked with the same colors (see Figure 14). This approach arranges the subject categories in alphabetical order, which is helpful to FI users to choose the desired categories directly. However, FD users, who seem more easily overwhelmed by the number of choices (Chen, 2002a), can activate additional support to identify the relevant subject categories.

\section{Conclusions}

In this work we investigated the relationship between users' cognitive styles and their response to the interface design of Web directories. Our findings suggest that cognitive style influences user's reactions to interface features. Thus, it is important to ensure that the design of Web directories accommodate the requirements of different cognitive style groups so that every user benefits equally from them. In this context, versatility in the interface design would accommodate a variety of individuals, rather 


\begin{tabular}{|c|c|}
\hline 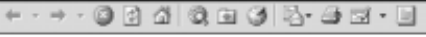 & Bit $-8 x$ \\
\hline $\begin{array}{l}\text { Arts }>\text { Movie }>\text { Multimedia } \\
\text { Sub-Categories } \\
\text { Audio } \\
\text { Back to the Future Series } \\
\text { Beautiful Thing } \\
\text { Desktop Customization } \\
\text { James Bond series } \\
\text { Matrix series } \\
\underline{\text { Posters }} \\
\text { Psycho - 1960 } \\
\underline{\text { Star Wars Movies }} \\
\text { Video }\end{array}$ & 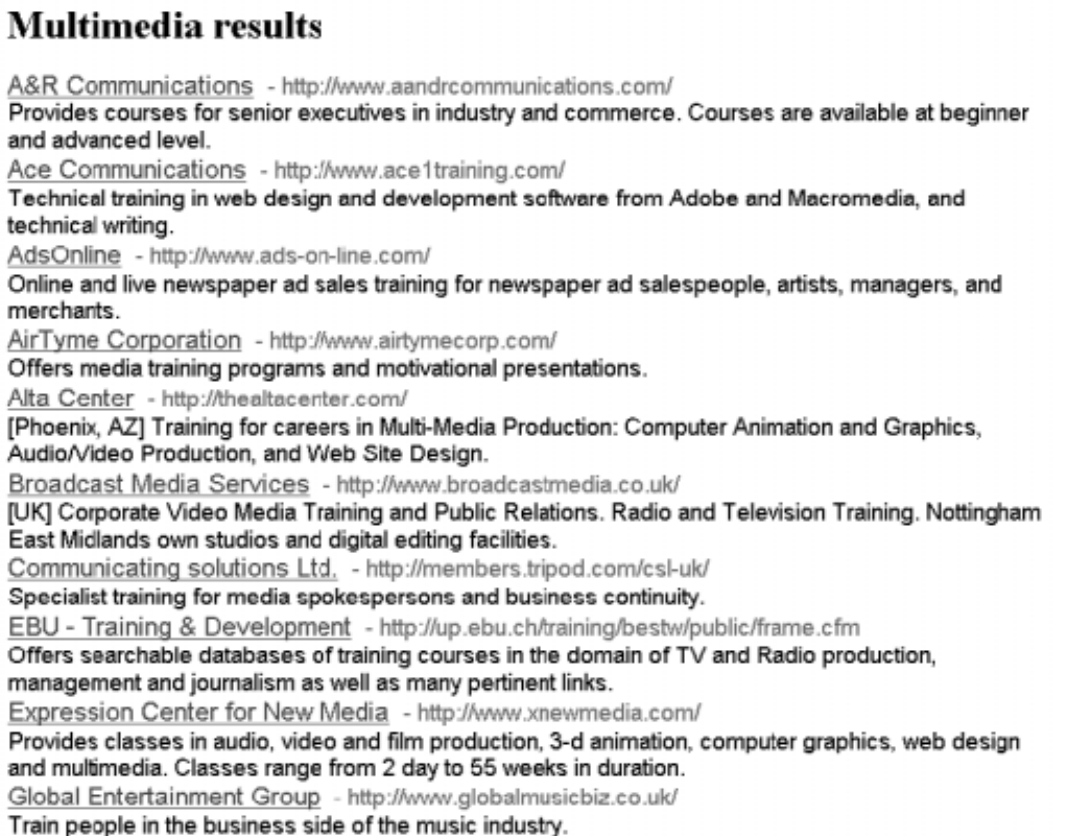 \\
\hline
\end{tabular}

FIG. 12. Organization of main categories for FI/FD users.

\section{Intelligent Directory}

\begin{tabular}{|c|c|c|}
\hline$\underline{\text { Agriculture }}^{\circledR}$ & $\underline{\text { Education }}^{\circledR}$ & Psychology \\
\hline Arts \& Humanities & $\underline{\text { Engineering }}^{\mathbb{1}}$ & $\underline{\text { Recreation \& Sport }}^{\mathbb{}}$ \\
\hline Business \& Economy & $\underline{\text { Entertainment }}^{t}$ & $\underline{\text { Religion }}^{\circledR}$ \\
\hline Chemistry & $\underline{\text { Government }}^{\circledR}$ & $\underline{\text { Science }}^{\circledR}$ \\
\hline$\underline{\text { Computers \& Internet }}^{\oplus}$ & $\underline{\text { Health }}^{\mathbb{1}}$ & $\underline{\text { Social Sciences }}^{\text {}}$ \\
\hline Design \& Art ${ }^{\circledR}$ & $\underline{\text { Law }}$ & $\underline{\text { Society \& Culture }}^{\text {而 }}$ \\
\hline \multicolumn{3}{|c|}{ Click to get relevant topics. } \\
\hline \multicolumn{3}{|c|}{ FIG. 13. Organization of subject categories for FI users. } \\
\hline \multicolumn{3}{|c|}{$\begin{array}{l}\text { than a particular user group. To achieve this aim, this study } \\
\text { developed a flexible interface incorporating the preferences } \\
\text { of different cognitive style groups. The design rationale of } \\
\text { this flexible interface can be used to improve existing Web } \\
\text { directories, with the final goal being to create other Web- } \\
\text { based applications, such as digital libraries, Web-based } \\
\text { learning, and electronic journals, that can be tailored to the } \\
\text { preferences associated with each cognitive style. } \\
\text { This study has shown the importance of understanding } \\
\text { cognitive styles in the development of Web directories, but it } \\
\text { was only a small-scale study. Further studies need to be } \\
\text { undertaken with a larger sample to provide additional }\end{array}$} \\
\hline
\end{tabular}

\section{Intelligent Directory}

\begin{tabular}{|c|c|c|}
\hline Agriculture $^{\mathbb{R}}$ & $\underline{\text { Education }}^{\text {网 }}$ & Psychology \\
\hline Arts \& Humanities & $\underline{\text { Engineering }}^{\text {ब }}$ & $\underline{\text { Recreation \& Sport }}^{\mathbb{R}}$ \\
\hline Business \& Economy & $\underline{\text { Entertainment }}^{\mathbb{E}}$ & $\underline{\text { Religion }}^{\text {R }}$ \\
\hline Chemistry & $\underline{\text { Government }}^{\mathbb{1}}$ & $\underline{\text { Science }}^{\text {田 }}$ \\
\hline Computers \& Internet & $\underline{\text { Health }}^{\mathbb{1}}$ & 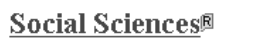 \\
\hline Design \& Art & $\underline{\text { Law }}$ & $\underline{\text { Society \& Culture }}^{\text {而 }}$ \\
\hline
\end{tabular}

Click 1 to get relevant topics.

FIG. 14. Organization of subject categories for FD users.

evidence. There is also a need to conduct further research to examine how users' cognitive styles influence their preferences of search options provided by search engines and library catalogues. Such research should also be conducted within a more sophisticated multimedia interface, including the presentation of animation and video. It would be interesting to see how different cognitive style groups perceive multimedia interface features. The findings of such studies could be integrated together to build robust user models for the development of personalized Web directories that can accommodate the preferences associated with different cognitive styles. 


\section{Acknowledgment}

The authors are grateful for the support of the Engineering and Physical Sciences Research Council (EPSRC Grant References: GR/R57737/01 and GR/R92554/01).

\section{References}

Archer, N.P., Head, M.M., \& Yuan, Y. (1996) Patterns in information search for decision making: the effects of information abstraction. International Journal of Human-Computer Studies, 45(5), 599-616.

Ash, B. (1986). Identifying learning styles and matching strategies for teaching and learning (Report No. JC860277). East Lansing, MI: National Center for Research on Teacher Learning. (ERIC Document Reproduction Service No. ED 270142)

Blandford, A., Stelmaszewska, H., \& Bryan-Kinns, N (2001). Use of multiple digital libraries: A case study. Proceedings of the Joint Conference on Digital Libraries '01. New York: ACM Press.

Carter, E.W. (2002). Doing the best you can with what you have: Lessons learned from outcomes assessment. Journal of Academic Librarianship, $28,36-41$

Chanlin, L. (1998). Students' cognitive styles and the need for visual control in animation. Journal of Educational Computing Research, 19(4), 351-363.

Chen, S.Y. (2002a). A cognitive model for non-linear learning in hypermedia programmes. British Journal of Educational Technology, 33(4): 453-464.

Chen, S.Y. (2002b, December). The relationships between individual differences and the quality of learning outcomes in web-based instruction. In Proceedings of the ICEB Second International Conference on Electronic Business, Taipei, Taiwan.

Chen, S.Y., \& Ford, N.J. (1998). Modelling user navigation behaviours in a hypermedia-based learning system: An individual differences approach. International Journal of Knowledge Organization, 25(3), 67-78.

Chen, S.Y., \& Macredie, R.D. (2002). Cognitive styles and hypermedia navigation: Development of a learning model. Journal of the American Society for Information Science and Technology, 53(1), 3-15.

Chen, S.Y., \& Macredie, R.D. (2004) Cognitive modelling of student learning in web-based instructional programmes. International Journal of Human-Computer Interaction, 17(3), 375-402.

Chin, J.P., Diehl, V.A., \& Norman, K.L. (1988) Development of an instrument measuring user satisfaction of the human-computer interface. ACM Computer-Human Interaction '88 Proceedings (pp. 213-218). New York: ACM Press.

Chou, C., \& Lin, H. (1997, February). Navigation maps in a computernetworked hypertext learning system. In Proceedings of the Annual Meeting of the Association for Educational Communications and Technology, Albuquerque, NM.

Chuang, Y.-R. (1999). Teaching in a multimedia computer environment: A study of effects of learning style, gender, and math achievement. Interactive Multimedia Electronic Journal of Computer-Enhanced Learning, 1(1) 1999. Retrieved September 19, 2004, from http://imej.wfu.edu/articles/1999/1/10/

Davis, J.K., \& Cochran, K.F. (1989) An information processing view of field dependence-independence. Early Child Development and Care, 51, $31-47$.

Despotopoulos, I., Korinthios, G., Nasios, I., \& Reisis, D. (1999). Developing an efficient model for evaluating WWW search engines. In Proceedings of the 17th IASTED International Conference. Applied Informatics. Alberta, Canada: ACTA Press.

Dufresne, A., \& Turcotte, S. (1997). Cognitive style and its implications for navigation strategies. In B. Boulay \& R. Mizoguchi (Eds.), Artificial intelligence in education knowledge and media learning system (pp. 287-293). Amsterdam: IOS Press.

Ford, N., \& Chen, S.Y. (2000). Individual differences, hypermedia navigation and learning: An empirical study. Journal of Educational Multimedia and Hypermedia, 9(4), 281-312.
Ford, N., \& Chen, S.Y. (2001). Matching/mismatching revisited: An empirical study of learning and teaching styles. British Journal of Educational Technology, 32(1), 5-22.

Ford, N., \& Ford, R. (1993). Towards a cognitive theory of information accessing: An empirical study. Information Processing \& Management, 29(5), 569-585

Ford, N., Wilson, T., Foster, A., Ellis, D., \& Spink, A. (2002) Information seeking and mediated searching. Part 4. Cognitive styles in information seeking. Journal of the American Society for Information Science and Technology, 53(9), 728-735.

Ford, N., Wood, F., \& Walsh, C. (1994). Cognitive styles and online searching. Online and CD-ROM Review, 18(2), 79-86.

Fullerton, K. (2000). The interactive effects of field dependenceindependence and Internet document manipulation style on student achievement from computer-based instruction. Unpublished doctoral dissertation, University of Pittsburgh.

Goodenough, D. (1976). The role of individual differences in field dependence as a factor in learning and memory. Psychological Bulletin, 83, 675-694.

Harrison, A.W., \& Rainer, R.K. (1992). The influence of individual differences on skill in end-user computing. Journal of Management Information Systems, 9(2), 93-111.

Hix, D., \& Hartson, H.R. (1993). Developing user interfaces: Ensuring usability through product and process. New York: Wiley.

Hobbs, L. (1999). Designing Internet homepages made simple. Oxford: Made Simple Books.

Hong, X. (2003). Supporting ease-of-use and user control: Desired features and structure of Web-based online IR systems. Information Processing \& Management, 39(6), 899-922.

Hook, K. (2000) Steps to take before intelligent user interfaces become real, Interacting with Computers, 12(4), 409-426.

Jonassen, D.H., \& Grabowski, B. (1993). Individual differences and instruction. Allyn \& Bacon, New York.

Karvonen, K. (1999, November). Creating trust. In Proceedings of the 2nd Nordic Workshop on Security, Kista, Sweden.

Ke, H., Kwakkelaarb, R., Taic, Y., \& Chen, L. (2002) Exploring behavior of E-journal users in science and technology: Transaction log analysis of Elsevier's ScienceDirect OnSite in Taiwan. Library \& Information Science Research, 24(3), 265-291.

Kinshuk. (1996). Effectiveness of intelligent tutoring tools interfaces in relation to student, learning topic and curriculum characteristics. Unpublished doctoral dissertation, De Montfort University.

Langley, P. (1999). User modelling in adaptive interfaces. In Proceedings of the Seventh International Conference on User Modelling (pp. 357-370). New York: Springer.

Leader, L.F., \& Klein, J.D. (1996). The effects of search tool type and cognitive style on performance during hypermedia database searches. ETR \& D, 44(2), 5-15.

Lee, C.H. (1994). The effects of auditory cues in interactive multimedia and cognitive style on reading skills of third graders. Unpublished doctoral dissertation, University of Pittsburgh. Lewis, B.J. (2002, Spring). Computer screen readability of foreground/background color combinations and font types. Retrieved September 19, 2004, from http://blewis.dyndns.org/psych/readability_study.pdf

Liaw, S., \& Huang, H. (in press). An investigation of user attitude toward search engines as an information retrieval tool. Computers in Human Behavior.

Lin, H.X., Choong, Y.Y., \& Salvendy, G. (1997) A proposed index of usability: A method for comparing the relative usability of different software systems. Behaviour and Information Technology, 16(4), 267-278.

Lindgaard, G. (1994). Usability testing and system evaluation: A guide for designing useful computer systems. London: Chapman \& Hall.

Ling, J., \& Schaik, P. (2002) The effect of text and background colour on visual search of web pages. Display, 23, 223-230.

Marchionini, G., Plaisant, C., \& Komlodi, A. (1998). Interfaces and tools for the Library of Congress National Digital Library Program. Information Processing \& Management, 34(5), 535-555. 
Marrison, D.L., \& Frick, M.J. (1994). The effect of agricultural students' learning styles on academic achievement and their perceptions of two methods of instruction. Journal of Agricultural Education, 35(1), 26-30.

Messick S. (1976). Individuality in learning. San Francisco: Jossey-Bass.

Näsänen, R., Karlsson, J., \& Ojanpää, H. (2001). Display quality and the speed of visual letter search. Displays, 22, 107-113.

Palmquist, R.A., \& Kim, K.-S. (2000). Cognitive style and on-line database search experience as predictors of Web search performance. Journal of the American Society for Information Science, 51(6), 558-66.

Pask, G. (1976). Styles and strategies of learning. British Journal of Educational Psychology, 46, 128-48, 1976.

Reiff, J.C. (1996). At-risk middle level or field dependent learners. Claring House, 69(4), 231-234.

Riding, R.J. (1991). Cognitive styles analysis. Birmingham, UK: Learning and Training Technology.

Riding, R.J., \& Cheema, I. (1991) Cognitive styles-An overview and integration. Educational Psychology, 11(3/4), 193-215.

Riding R.J., \& Grimley, M. (1999). Cognitive style, gender, and learning from multimedia materials in 11-year-old children. British Journal of Education Technology, 30(1), 43-56.

Riding, R., \& Rayner, S.G. (1998). Cognitive styles and learning strategies. London: David Fulton Publisher.

Rogers, S., \& Iba, W. (2000). Adaptive user interfaces. AAAI Symposium (Technical Report 55-00-01). Menlo Park, CA: AAAI Press.

$\mathrm{Su}$, L.T. (1991). An investigation to find appropriate measures for evaluating interactive information retrieval. Unpublished doctoral dissertation, State University of New Jersey.
Travis, D. (1991). Effective colour displays. London: Academic Press.

Weller, H.G., Repman, J., \& Rooze, G.E. (1994). The relationship of learning, behavior, and cognitive styles in hypermedia-based instruction: Implications for design of HBI. Computers in the Schools, 10(3/4), 401-420.

White, M.D., \& Ivonen, M. (2001) Questions as a factor in web search strategy. Information Processing and Management, 37, 721-740.

Witkin, H.A. (1950). Individual differences in ease of perception of embedded figures. Journal of Personality, 19, 1-15.

Witkin, H.A., \& Asch, S.E. (1948). Studies in space orientation: IV. Further experiments on perception of the upright with displaced visual fields. Journal of Experimental Psychology, 38, 762-782.

Witkin, H.A., \& Goodenough, D.R. (1981). Cognitive styles: Essence and origins: Field dependence and field independence. New York: International Universities Press.

Witkin, H.A., Moore, C.A., Goodenough, D.R., \& Cox, P. (1977). Fielddependent and field independent cognitive styles and their educational implications. Review of Educational Research, 47(1), 1-64.

Witkin, H.A., Oltman, P.K., Raskin, E., \& Karp, S.A. (1971). A manual for the group embedded figures test. Palo Alto, CA: Consulting Psychologists Press.

Yu, L., \& Lin, T. (1999) What should we consider for user interface design? Retrieved September 19. 2004, from http://slis-two.lis.fsu.edu/ design/ interface/index.html

Zoe, L.R., \& DiMartino, D. (2000). Cultural diversity and end-user searching: An analysis by gender and language background. Research Strategies, 17(4), 291-305. 